\title{
Polemik Pengesahan Omnibus Law: UU Cipta Kerja Dalam Perspektif Sosiologi Hukum
}

\author{
Karinina Anggita Farrisqi, Agus Machfud Fauzi \\ Fakultas IImu Sosial dan Hukum, Universitas Negeri Surabaya, Indonesia. E-mail: \\ anggitakarinina@gmail.com
}

\begin{abstract}
A law with a concept on the omnibus law in the world of law in the State of Indonesia is a new perspective in the field of law. The point in omnibus law is different from the meaning, nature, and concept of legal norms in existing laws. We can also interpret this concept as a way of settling the forms of regulation in legislation into law and which in the end have consequences for revoking some invalid regulations. With the use of a new perspective like this, of course, people's thinking is also increasingly modern, including following the flow of globalization. In this era of globalization, there are certainly many incidents in the spread of hoax news. This problem is carried out by qualitative research methods and using several theories. The subject matter to be discussed can also be found in the conclusion that the perspective used by the drafters of the law is increasingly modern which will also provide the potential for the spread of hoaxes from people who follow the flow of globalization. Therefore, if the government and the DPR enforce themselves in making laws with the concept of the omnibus law, then the formation process needs to follow the method of prolegnas, has a good academic script, and is not in a hurry by involving stakeholders and the community.
\end{abstract}

Keywords: Omnibus Law, Hoax, Globalization

\section{Pendahuluan}

Di awal tahun 2020 pemerintah tengah mempersiapkan Rancangan Undang-Undang (RUU) Cipta Kerja yang dimana menggunakan konsep Omnibus Law. RUU ini sedang dipersiapkan oleh Pemerintah untuk dijadikan sebuah skema untuk upaya membangun perekonomian Indonesia agar menarik para investor bersedia dalam menanamkan modalnya di Indonesia. Pemerintah memandang perlu adanya RUU Cipta Kerja ini karena tingginya angka pengangguran di Indonesia yang mencapai 7 juta jiwa sehingga diharapkan RUU ini mampu membuka lapangan kerja baru. Dua Konsep Omnibus Law ini merupakan konsep yang juga biasa digunakan dalam sistem perundang-undangan di Indonesia. Sistem ini biasanya disebut sebagai Undang-Undang sapu jagat karena mampu mengganti beberapa norma undang-undang dalam satu peraturan. Selain itu konsep ini juga dijadikan misi untuk memotong beberapa norma yang dianggap tidak sesuai dengan perkembangan zaman dan merugikan kepentingan negara. Di dalam RUU Cipta Kerja memiliki 11 klaster yang salah satu diantaranya mengatur tentang ketenagakerjaan, dimana klaster ini melingkupi 3 undang-undang yang dilebur menjadi satu yakni UndangUndang Nomor 13 tahun 2003 tentang ketenagakerjaan, Undang-Undang Nomor 40 tahun 2004 tentang sistem jaminan sosial, dan Undang-Undang Nomor 24 tahun 2011 tentang badan penyelenggara jaminan sosial. 
Pada klaster ketenagakerjaan ini Pemerintah berusaha keras untuk menyatukan atau merukunkan ketiga undang-undang tersebut agar sejalan sehingga mampu memberikan sebuah ruang kepada investor untuk melihat regulasi yang telah disempurnakan tanpa adanya rasa khawatir terhadap regulasi yang tumpang tindih dan mengakibatkan kerugian kepada investor itu sendiri.

Modernisasi merupakan sebuah proses perubahan dari satu arah ke arah yang lebih maju atau modern dan berdampak pada seluruh aspek kehidupan masyarakat (Rosana, 2011). Seluruh aspek kehidupan telah berubah mulai dari ekonomi, politik, kesehatan, sosial dan budaya. Salah satu aspek yang paling terasa perubahannya adalah aspek sosial, dimana cara berkomunikasi dan penyebaran infromasi lebih banyak dilakukan secara online melalui gawai. Sosial media merupakan sarana untuk berbagi informasi, namun apabila tidak diimbangi dengan kesadaran dan etika yang tepat dapat menyebabkan terjadinya penyebaran berita palsu atau yang biasa disebut hoax (Rahadi, 2017). Salah satu contohnya adalah penyebaran hoax tentang UU Cipta Kerja dengan konsep Omnibus Law yang belakangan ini kontroversial hingga menyebabkan demonstrasi di berbagai daerah. Pada awal tahun 2020, pemerintah mempersiapkan RUU Cipta Kerja yang nantinya akan dijadikan sebuah skema dalam rangka meningkatkan perekomonian Indonesia agar mengundang investor untuk menanamkan modal di Indonesia. Pemerintah membentuk RUU ini dengan menimbang banyaknya angka pengangguran di Indonesia yang mencapai 7 juta jiwa, sehingga dengan adanya RUU ini diharapkan dapat membuka lapangan kerja yang lebih banyak (Kurniawan \& Dewanto, 2020). Di dalam UU Cipta Kerja terdapat beberapa peraturan yang tersebar menjadi hoax di masyarakat, seperti uang pesangon dihilangkan, penghapusan hak cuti, perusahaan dapat mem-PHK karyawan kapanpun secara sepihak dan lain-lain. Beberapa hoax tersebut menyebar dengan cepat melalui media sosial bahkan menjadi trending topic yang menyulut emosi masyarakat dan mendorong mereka untuk melakukan demonstrasi. Fenomena tersebut merupakan dampak dari penggunaan media sosial yang kurang bijak.

Ini merupakan salah satu permasalahan yang sedang dihadapi oleh Pemerintah, anggota DPR, dan masyarakat sehingga pengesahan RUU Cipta Kerja ini memakan waktu yang cukup lama. Problematika ini masih terus di suarakan oleh kaum buruh dan masyarakat untuk menolak adanya RUU tersebut ketika DPR sedang membahas RUU Cipta Kerja ini dalam rapatnya. Pemerintah dan DPR seharusnya sudah tahu bahwa adanya sebuah hukum yang berlaku sudah semestinya memberikan rasa adil kepada masyarakat dan mampu memberikan kebahagiaan kepada masyarakat. Namun disisi lain Pemerintah juga tetap harus berupaya dan konsisten untuk menumbuhkan perekonomian rakyat sebagai jalan untuk mencapai kesejahteraan sosial. Untuk masyarakat Indonesia yang sekarang sedang berada dalam kemajuan teknologi maupun kemajuan cara berfikir untuk selalu menggunakan teknologi dan cara berfikir modern yang baik untuk meminimalisir adanya kejadian yang tidak diinginkan. 


\section{Metode}

Paradigma yang digunakan adalah paradigma deskriptif dengan pendekatan kualitatif, Berdasarkan kasus masalah yang sedang beredar dalam masyarakat tentang penyebaran hoax terhadap undang - udang cipta kerja, kami ingin menganalisis dengan menggunakan teori Habermas yaitu teori runag public, karya tulis ini berjenis kajian literature dengan menggunakan refrensi jurnal nasional dan menggunakan teori literasi media jeknis untuk mendukung hasil analisis. Hoax adalah berita yang tersebar dalam masyarakat namun kebenarannya tidak dapat ditemukan sehingga kesimpulan yang dapat diambil bahwa kabar yang disebarkan adalah berita palsu. Hoax disebarluaskan oleh pihak yang tidak bertanggung jawab dengan tujuan untuk menjatuhkan reputasi seseorang atau menimbulkan konflik didalam masyarakat. Hoax yang ada pada masyarakat modern tidak dapat diantisipasi karena dengan kemajuan teknologi yang ada membantu pihak yang tidak bertanggung jawab dalam meluncurkan aksinya. Teknik yang digunakan pihak yang tidak bertanggung jawab dengan menggunakan media sosial masyarakat akan terarah untuk percaya dengan mudah akan isu - isu yang berkembang (Irianti, 2018). Tujuan yang diinginkan adalah menyebarkan berita tidak benar agar orang lain percaya kemudian membuatnya orang yang percaya menyebarluakan kepada teman dan keluarga terdekat, tanpa adanya penyaringan berita secara intenif.

Adapun data yang digunakan dalam penelitian ini adalah data sekunder. Data sekunder yang digunakan dalam penelitian ini diperoleh dari berbagai dokumentasi tertulis seperti artikel jurnal, buku, surat kabar, ataupun berbagai informasi internet yang memiliki tema yang serupa terkait Omnibus Law dan respon masyarakat terhadap Omnibus Law (UU Cipta Kerja). Data yang telah diperoleh akan di analisis menggunakan beberaopa tahap teknik analisis data, meliputi reduksi data, penyajian data dan terakhir penarikan kesimpulan.

\section{Hasil dan Pembahasan}

Teori Ruang Publik yang diciptakan Habermas dijelaskan dalam karyanya The Structural Transformation of The Publik Sphere ruang public pada masa modern akan mengalami depolitisasi kerangka public yang awalnya digunakan sebagai tempat diskusi permasalahan public aat ini berubah menajdi tempat debat, diskusi rational serta penyebaran berita bohong. Refeodalisasi ruang public akan mencipatakan opini public sebuah opini yang tidak terbentuk atas konsesus dan perdebatan namun dibentuk oleh adanya kelompok elite media, ekonomi dan politik. Habermas mengikuti jejak pemikiran dari Wirtgenstein yang membaha tentang dialog berfungsi sebagai alat untuk membangun bersama pemahaman dan kesepatakan masyarakat baik antarindividu dan kelompok. Menurut Habermas ada 2 korban yang akan menjadi hegemoni pasar dalam atas demokrasi dan ruang public pertama wilayah sosial yang ada dalam masyarakat tidak lagi menjadi bagan diskursus rasional namun menjadi komoditas hiburan sehingga dapat dikonsumsi secara pasif oleh pemirsa, kedua wilayah politis partai politik yang diciptakan untuk menjadi bagan yang berfungsi dalam penyerapan segala aspirasi masyarakat dan mengadakan pembagunan dalam yang merupakan tujuan utama partai menjadi komoditas politik yang dipertukarkan dimeja parlemen untuk menjamin kemenangan dalam voting sehingga akan menjadi komoditas pencitraan bagi wakil rakyat atau 
penguasa (Habermas, 2015). Masyarakat yang secara pasif mengkonsumsi produk dari media massa diharapakan untuk lebih cerdas dan memilah mana produk media yang asli dan produk media yang bukan asli, penyaringan media selalu diperlukan dalam kehidupan masyarakat melihat dampak globalisasi semakin merambah dan menyebar sehingga segala berita yang bersifat pasif belaka dapat keluar masuk melalui media masa. Masyarakat diharapkan dapat selalu bersifat kritis dalam menikmati produk media masaa, karena mayarakat berada dalam posisi pendengar berita yang cenderung akan disebarkan melalui komunikasi kepada orang lain (Sumaryanto, 2010).

3.1. Berdasarkan hasil klarifikasi yang didapatkan melalui media sosial Instagram Dewan Perwakilan Rakyat Republik Indonesia

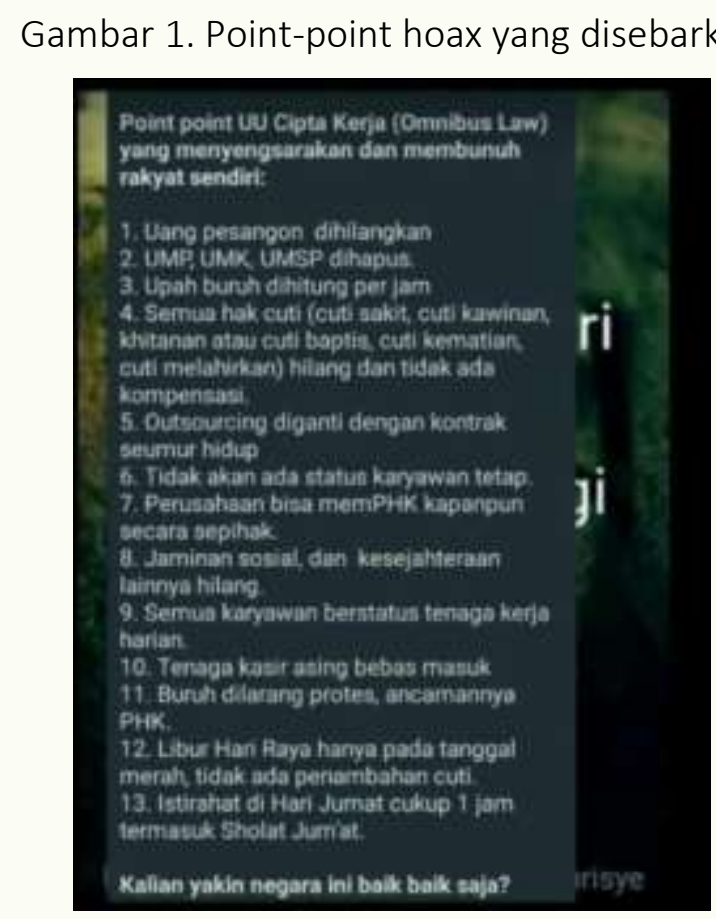

Sumber : Salah satu grup di WhatsApp

Ada 12 berita yang menurut DPR RI tidak benar atau dinyatakan hoax mengenai Omnibus Law RUU Cipta Kerja yang beredar didalam masyarakat

1. Uang Pesangon buruh akan dihilangkan?

DPR membantah hal tersebut dengan menyebutkan UU BAB IV KETENAGAKERJAAN - Pasal 89 tentang perubahan pasal 156 Ayat 1 UU 13 Tahun 2003: dalam hal terjadi pemutusan hubungan kerja pengusaha diwajibkan membayar uang pesangon atau uang penghargaan masa kerja

2. UMP, UMK dan UMSP dihapukan?

DPR membantah dengan menyebutkan UU BAB IV KETENAGAKERJAAN - Pasal 89 tentang perubahan pasal 88 C UU 13 Tahun 2003. Ayat 1 Gubernur tetap menetapkan upah minimum sebagai jarring pengaman. Ayat 2 Upah minimum sebagaimana dimaksudkan pada ayat 1 merupakan upah minimum provinsi

3. Upah Buruh dihitung per jam? 
DPR membantah bahwa UU BAB IV KETENAGAKERJAAN - Pasal 89 tentang perubahan pasal 88 B UU 13 Tahun 2003. Upah ditetapkan berdasarkan satuan waktu atau satuan hasil.

4. Keseluruhan hak cuti akan dihilangkan dan tidak mendapatkan kompensasi? DPR tetap membantah dalam UU BAB IV KETENAGAKERJAAN - Pasal 89 tentang perubahan pasal 79 UU 13 Tahun 2003. Ayat 1 pengusaha wajib membei : waktu istirahat dan cuti

5. Outsourcing akan diganti dengan kontrak seumur hidup?

DPR membantah bahwa UU BAB IV KETENAGAKERJAAN - Pasal 89 tentang perubahan pasal 66 Ayat 1 UU 13 Tahun 2003 : Hubungan Kerja antara perusahaan dan buruh didasarkan pada perjanjian kerja waktu tidak tertentu.

6. Tidak ada status karyawan tetap?

DPR membantah bahwa UU BAB IV KETENAGAKERJAAN - Pasal 89 tentang perubahan pasal 56 UU 13 Tahun 2003 : perjanjian kerja dibuat untuk waktu tertentu.

7. Perusahaan bebas memPHK kapanpun secara sepihak?

DPR tetap membantah bahwa UU BAB IV KETENAGAKERJAAN - Pasal 90 tentang perubahan pasal 151 UU 13 Tahun 2003 : Ayat 1 pemutusan hubungan kerja berdasarkan kesepakatan. Ayat 2 penyelesaian pemutusan hubungan kerja dilakukan melalui prosedur dengan ketentuan peraturan perundang - undangan.

8. Jaminan Sosial dan Kesejahtreraan lainnya hilang?

DPR membantah pada pasal UU BAB IV KETENAGAKERJAAN - Pasal 89 tentang perubahan pasal 18 UU 40 Tahun 2004 : jaminan sosial meliputi (jaminan kesehatan, jaminan kecelakaan kerja, jaminan hari tua, jaminan pension, jaminan kematian, dan kehilangan pekerjaan)

9. Semua karyawan berstatus tenaga kerja harian?

DPR membantah dengan menyebutkan bahwa UU BAB IV KETENAGAKERJAAN Pasal 89 tentang perubahan pasal 56 Ayat 1 UU 13 Tahun 2003 : perjanjian kerja dibuat untuk waktu tertentu dan tidak tertentu.

10. Tenaga Kerja Asing bebas masuk?

DPR membantah dengan menyebutkan bahwa UU BAB IV KETENAGAKERJAAN Pasal 89 tentang perubahan pasal 42 Ayat 1 UU 13 Tahun 2003 : setiap pemberi kerja yang memperkerjakan tenaga kerja asing harus melalui syarat dan peraturan

11. Buruh tidak diizinkan protes jika melanggar akibat yang diterima PHK?

DPR hanya membantah namun tidak memberikan penjelasan resmi seperti dengan menyebutkan nomor UU.

12. Libur hari raya hanya khusus tanggal merah dan tidak ada penambahan cuti? DPR membantah bahwa tanggal merah dan penambahan tanggal cuti memang tidak diatur dalam Undang - Undang tetapi berdasarkan aturan pemerintah.

3.2. Klarifikasi Pemerintah Indonesia Mengenai Hoax dalam RUU Cipta Kerja setelah terjadi demonstransi dibeberapa daerah di Indonesia

Menurut presiden RI Bapak Joko Widodo terjadinya unjuk rasa atau demo penolakan Undang-Undang cipta kerja pada dasarnya dilatarbelakangi oleh disinformasi mengenai substansi Undang-Undang dan hoax media sosial. 12 berita menurut DPR RI mengenai 
Omnibus Law yang sudah dijelaskan di atas telah diklarifikasi oleh bapak presiden, dan dengan tegas semuanya dinyatakan tidak benar. Salah satu contoh, terdapat informasi yang menyebutkan ada penghapusan UMP, UMK, dan UMSP. Bapak presiden menyatakan bahwa itu tidak benar, dan menjelaskan bahwa faktanya Upah Minimum Regional tetap ada. Kabar hoax selanjutnya menyebutkan bahwa upah minimum dihitung per jam, dan bapak presiden mengatakan bahwa itu juga tidak benar. Tidak ada perubahan dengan sistem yang sekarang, upah dihitung berdasarkan waktu dan berdasarkan hasil.

Undang-Undang Cipta Kerja tidak melakukan resentralisasi kewenangan dari pemerintah daerah ke pemerintah pusat. Perijinan berusaha dan pengawasan tetap dilakukan oleh pemerintah daerah sesuai dengan Norma Standar Prosedur dan Kriteria (NSPK) yang ditetapkan oleh pemerintah pusat, agar dapat tercipta standar pelayanan yang baik di seluruh daerah. Undang-undang Cipta Kerja memerlukan banyak Peraturan Pemerintah (PP) dan Peraturan Presiden, maka dari itu akan muncul banyak PP dan Perpres yang akan diselesaikan paling lambat 3 bulan setealah diundangkan. Pemerintah membuka dan mengundang masukan dan usulan-usulan dari masyarakat dan juga dari daerah. Pemerintah memiliki keyakinan bahwa melalui Undang-Undang Cipta Kerja akan ada jutaan pekerja yang dapat memperbaiki kehidupannya dan penghidupan untuk keluarga mereka. Jika masih ada ketidakpuasaan atau penolakan terhadap UU Cipta kerja dapat melakukan uji materai atau yudisial review yang diajukan kepada Mahkama Konstitusi (MK).

\subsection{Berita Hoax dalam Prespektif Literasi Media}

Proses Literasi media adalah sebuah proses untuk mengakses, mengevaluasi dan serta menganalisa informasi yang diterima dari media, dengan menggunakan proses literasi maka pendengar media akan lebih kritis dalam menerima informasi. Proses literasi media melindungi pendengar agar tidak terjebak dalam berita hoax. Jeknis et al membagi proses literasi menjadi 12 play performance, simulation, appropriation, multitasking, distributed cognition, collective intelligence, judgment, transmedia navigation, networking, negotiation, visualization. 12 proses literasi ini dapat digunakan dan disesuaikan dengan penelitian yang dilakukan oleh peneliti. Penelitian literasi ini hanya mengguanakan 5 proses literasi media.

1. Play kemampuan yang pertama ini diartikan sebagai kemampuan dalam menggunakan. Garis besarnya dalam proses play tidak hanya meliputi pengguna dalam menggunakan tetapi juga bagaimana pengguna mengeksplor media baru yang diguankan sehingga akan muncul hubungan antara pikiran dengan pengguna. Bagi pengguna yang sering menggunakan media maka akan lebih peka dengan informasi yang didapatkan untuk menambah dan membentuk struktur ilmu pengetahuan. Berkembangnya media sosial seperti saat ini membuat masyarakat dengan mudah memilih media sosial yang akan digunakan dalam mencari informasi, dengan kecanduan teknologi anak muda saat ini membuatnya semakin bergantung pada infomasi yang ada melalui gadget. Berita hoax yang menyebar dalam masyarakat mengenai adanya RUU Cipta Kerja yang menimbulkan banyak kontra oleh masyarakat Indonesia disebarluaskan melalaui media sosial WhatsApp, Instagram, Twitter dan media sosial lainnya. Masyarakat yang mengkonsumsi berita melalui media sosial 
tentang RUU melalui aplikasi yang digunakan, kemudian menyebarluaskan berita yang diterima kepada saudara sampai teman terdekat.

2. collective intelligence kemampuan yang kedua adalah kemampuan untuk menyatukan pengetahuna yang dimiliki oleh pengguna media sosial akan informasi yang didapat kemudian membandingkan pendapatnya dengan orang lain. Setelah proses pembandingan selesai didalam media sosial akan terbentuk komunitas baru yang didalamnya berisi anggota yang memiliki pendapat yang sama, tujuan yang sama. Pembentukan sebuah komunitas tidak hanya sebatas hal - hal yang disukai seperti tokoh idola namun informasi yang berjenis politik, sosial dan budaya. Penyebaran berita Hoax mengenai RUU Cipta Kerja diterima masyarakat melalui media sosial, ketika informasi ini dibaca oleh seluruh orang maka akan terbentuk komuntias yang kontra dengan adanya RUU Cipta Kerja seperti grub : Tolak RUU dengan peresmian yang sepihak, Tolak RUU penindasan masyarakat kelas bawah, Tolak RUU yang mengedepankan kelas pengusaha, Batalkan RUU dan grub lainnya melalui beberapa aplikasi media sosial. Tujuan komunitas yang dibentuk masyarakat melalui media sosial digunakan untuk menyatupadukan tujuan bersama untuk menolak RUU dengan melakukan demo secara bersama - sama dengan waktu dan tempat yang telah disepakati komunitas.

3. Judgment proses ketiga dalam literasi media penikmat media sosial harus menggunakan kemapuan untuk mengevaluasi kredibilitas dari sumber - sumber informasi yang diterima. Analisis Jeknis menyebutkan bahwa untuk membandingkan sumber Wikipedia dan Encyclopedia memiliki tingkat kredibilitas yang sama walaupun demikian tidak dapat dipastikan sumber resmi tidak memiliki tingkat kecatatan. Dengan demikian pendengar dan penikmat media sosial harus lebih berfikir mendalam untuk membaca sumber - sumber informasi dari prespektif kritis sehingga pembaca dapat menilai mana yang berifat fakta dan mana yang bersifat fakta dan hoax. Masyarakat yang menerima berita tentang adanya RUU Cipta Kerja yang mulai tersebar dari media sosial mempercayai isi RUU yang dianggap DPR sebagai hoax.

4. transmedia navigation pembaca harus memiliki kemampuan untuk mengikuti alur cerita dan informasi yang didapatkan karena consumen sebagai pemburu informasi tidak boleh terhenti atas waktu jika ingin mengkiritisi sebuah berita. Artinya jika pembaca memilih satu berita yang digunakan untuk memberikan hak atas kontra dari berita tersebut harus mengikuti perkembangan berita tersebut setiap hari, untuk mengantisipasi bahwa pendengar tidak salah dalam memberikan tanggapan kontra tentang berita tersebut. Munculnya kontra masyarakat mengenai RUU yang ada menimbulkan beberapa aksi demo yang dilakukan baik dari para buruh, mahasiswa dan masyarakat. Konflik kontra dari masyarakat kepada para wakil rakyat saat terjadi demo belum memiliki titik terang untuk mengatasi masalah tersebut.

5. Networking kemampuan terakhir yang digunakan masyarakat yaitu menyebarkan informasi yang didapatkann dari sini jaringan sosial yang sependapat mulai semakin banyak muncul dan berkumpul menjadi komunitas yang semakin besar. Penyebaran berita melalui media sosial baik media hoax maupun media yang benar guna untuk membuka forum diskusi untuk menganalisis suatu kebenaran dari informasi. Penyebaran berita tentanf RUU Cipta Kerja yang isinya menindas masyarakat kecil semakin menyebar luas kemudian menjadikan emosi masyarakat terutama para 
buruh dan mahasiswa semakin memuncak akibatnya demo terjadi di beberapa daerah di Indonesia untuk menolak peresmian RUU Cipta Kerja atau Omnibus Law, kerusakan terjadi dimana - mana akibat demo yang terjadi secara brutal. Setelah terjadi beberapa kerusakan fasilitas umum pemerintah bersama dengan DPR memberikan klarifikasi terkait isi RUU Cipta Kerja yang beredar dalam masyarakat adalah berita hoax. Masyarakat yang mengetahui klarifikasi tersebut tidak begitu mudah percaya karena ada kontradiksi antara anggota DPR yang berusaha mengemukakan pendapatnya tentang isi RUU namun tidak dihiraukan oleh ketua DPR pada saat sidang peresmian sampai terjadinya pemutusan saluran mic kepada anggota DPR yang mengkritisi RUU Cipta Kerja oleh atasan DPR tersebar luas dimasyarakat. Dengan demikian masyarakat sudah mulai menggunakan pikiran, nalar dalam mengkritisi apa yang diterima masyarakat melalaui media sosial diimbangkan dengan pengetahuan yang dimiliki.

\section{Kesimpulan}

Di dalam RUU Cipta Kerja memiliki 11 klaster yang salah satu diantaranya mengatur tentang ketenagakerjaan, dimana klaster ini melingkupi 3 undang-undang yang dilebur menjadi satu yakni Undang-Undang Nomor 13 tahun 2003 tentang ketenagakerjaan, Undang-Undang Nomor 40 tahun 2004 tentang sistem jaminan sosial, dan UndangUndang Nomor 24 tahun 2011 tentang badan penyelenggara jaminan sosial. Sosial media merupakan sarana untuk berbagi informasi, namun apabila tidak diimbangi dengan kesadaran dan etika yang tepat dapat menyebabkan terjadinya penyebaran berita palsu atau yang biasa disebut hoax.

Ini merupakan salah satu permasalahan yang sedang dihadapi oleh Pemerintah, anggota DPR, dan masyarakat sehingga pengesahan RUU Cipta Kerja ini memakan waktu yang cukup lama. Untuk masyarakat Indonesia yang sekarang sedang berada dalam kemajuan teknologi maupun kemajuan cara berfikir untuk selalu menggunakan teknologi dan cara berfikir modern yang baik untuk meminimalisir adanya kejadian yang tidak diinginkan. Seperti akan terjadinya penyebaran hoax olehg oknum yang tidak bertanggung jawab dan suka membuat onar.

Hoax adalah berita yang tersebar dalam masyarakat namun kebenarannya tidak dapat ditemukan sehingga kesimpulan yang dapat diambil bahwa kabar yang disebarkan adalah berita palsu. Hoax yang ada pada masyarakat modern tidak dapat diantisipasi karena dengan kemajuan teknologi yang ada membantu pihak yang tidak bertanggung jawab dalam meluncurkan aksinya. Teknik yang digunakan pihak yang tidak bertanggung jawab dengan menggunakan media sosial masyarakat akan terarah untuk percaya dengan mudah akan isu - isu yang berkembang. Berita Hoax dalam Prespektif Literasi Media Proses Literasi media adalah sebuah proses untuk mengakses, mengevaluasi dan serta menganalisa informasi yang diterima dari media, dengan menggunakan proses literasi maka pendengar media akan lebih kritis dalam menerima informasi.

DPR membantah dengan menyebutkan bahwa UU BAB IV KETENAGAKERJAAN - Pasal 89 tentang perubahan pasal 42 Ayat 1 UU 13 Tahun 2003 : setiap pemberi kerja yang memperkerjakan tenaga kerja asing harus melalui syarat dan peraturan 11. 
Penyebaran berita tentang RUU Cipta Kerja yang isinya menindas masyarakat kecil semakin menyebar luas kemudian menjadikan emosi masyarakat terutama para buruh dan mahasiswa semakin memuncak akibatnya demo terjadi di beberapa daerah di Indonesia untuk menolak peresmian RUU Cipta Kerja atau Omnibus Law, kerusakan terjadi dimana - mana akibat demo yang terjadi secara brutal. Masyarakat yang mengetahui klarifikasi tersebut tidak begitu mudah percaya karena ada kontradiksi antara anggota DPR yang berusaha mengemukakan pendapatnya tentang isi RUU namun tidak dihiraukan oleh ketua DPR pada saat sidang peresmian sampai terjadinya pemutusan saluran mic kepada anggota DPR yang mengkritisi RUU Cipta Kerja oleh atasan DPR tersebar luas dimasyarakat. 


\section{Daftar Pustaka}

Amiruddin dan Zainal Asikin, Pengantar Metode Penelitian Hukum, (Jakarta: Raja Grafindo Persada, 2006).

F. Budi Hardiman. 1993. Menuju Masyarakat Komunikatif. Yogyakarta: Kanisius.

Jurgen Habernas. 2015. Ilmu dan Teknologi Sebagai Ideologi, Jakarta: LP3ES.

Sodikin. 2020. "Paradigma Undang-Undang Dengan Konsep Omnibus Law Berkaitan Dengan Norma Hukum Yang Berlaku Di Indonesia". Inferensi: Jurnal Rechts Vinding (Media Pembinaan Hukum Nasional) vol. 9 no. 1, April 2020.

Utomo, Pudjo. 2019. "Omnibus Law: Dalam Pespektif Hukum Responsif”. Inferensi: Jurnal Nurani Hukum. Vol. 2 no. 1, Juni 2019.

https://news.detik.com/kolom/d-5230318/menguji-dasar-sosiologis-uu-cipta-kerja http://berita.upi.edu/menyikapi-positif-ruu-omnibus-law/

Conflict of Interest Statement: The authors(s) declares that the research was conducter in the absence of any commercial or financial relationship that could be construed as a potential conflict of interest.

Copyright: (19 URLRey. This is an open access article distributed under the terms of the Creative Commons Attribution 4.0 International Licence (CC-By 4.0 ), which permits unrestricted use, distribution, and reproduction in any medium, provided the original author and source are credited.

UIR Law Review (UIRLRev) is an open access and peer-reviewed journal published by Faculty of Law, Universitas islam Riau; Indonesia. 